\title{
Community engagement in disaster recovery: Lessons from the aftermath of Nepal earthquake 2015
}

\author{
Ghorasainee Sanjeeb * \\ Graduate School of Global Governance, Meiji University, Tokyo, Japan
}

\author{
Keywords \\ Disaster recovery \\ Community engagement \\ Social capital \\ Nepal
}

Received: 02 January 2019

Accepted: 18 January 2019

Published: 20 February 2019

\begin{abstract}
This paper discusses the important role of social capital, networks, and community engagement in disaster recovery. This study takes the case of Nepal and analyzes the recovery and reconstruction activities done through direct initiative and active engagement of residents in Giranchaur village of Sindhupalchowk district after the devastating earthquake of 2015. Information was gathered based on primary data sources collected through field visits and analysis of secondary data. Two field visits were carried out in October 2017 and August 2018, respectively during which, direct observation and in-depth interviews were carried out with key informants and residents of Giranchaur. Available scholarly literature on the topic was reviewed, and two main policy documents were prepared in Nepal to guide the reconstruction and recovery process. The finding of this study shows that idea generated from the grassroots, lead by an able local leadership and implemented via existing social networks with active community engagement leads to sustainable recovery, as shown by the case study of Giranchaur village. Based on the evidence, the paper derives some lessons from experience in the aftermath of the Nepal Earthquake 2015 that have practical implications to policymakers when deciding future intervention strategies in disaster-affected communities.
\end{abstract}

(C) 2019 The Author(s). Published by TAF Publishing.

\section{INTRODUCTION}

On April 25, 2015, a magnitude 7.8 earthquake struck Nepal. This was followed by hundreds of aftershocks, most notably an aftershock of magnitude 7.3 on May 12, 2015 that further severed the damage. The earthquakes caused immense damage to life and property with nearly 9000 deaths, more than 22000 injured and lives of around 8 million people directly impacted. Nearly 800,000 private houses were damaged and further damage was done to cultural heritages and thousands of public buildings such as government offices and schools according to The National
Planning Commission (NPC). It estimated damage received from the losses in this earthquake to be valued at 7 billion US dollar. Out of which $58 \%$ was in social sectors, of which $86 \%$ was the housing sector (National Planning Commission (NPC), 2015). Sindhupalchowk (also spelled as Sindhupalchok) district, marked in Figure 1 below, was the worst affected among the 14 most hit districts out of 75 districts in the country. In Sindhupalchowk alone, 3570 people lost their lives and 89884 private houses were fully damaged. Nearly $95 \%$ of all the houses in the districts were damaged from the earthquake and required reconstruction.

*corresponding author: Ghorasainee Sanjeeb

†email: sanjgh09@gmail.com 


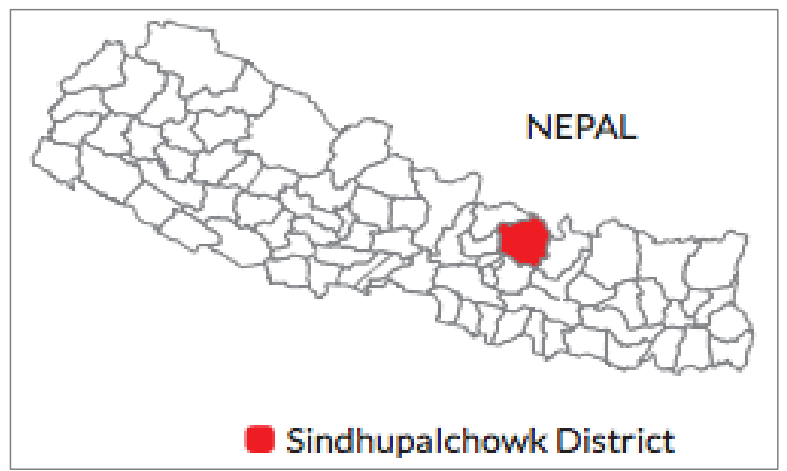

FIGURE 1. Sindhupalchowk district located in the map of Nepal (Source: Global Green Growth Institute (2018))

The government together with help from other national and international actors carried out immediate rescue and relief activities. Food, clothing and shelter, the primary lifeline had to be supplied to the affected population. The efficiency and effectiveness of government action in fulfilling this role is contested and is a matter of separate debate. However, after the immediate rescue and relief phase a larger problem was in front of the government, and that was the process of long-term recovery by reconstructing the damaged houses and building back communities better.

The delay in government action to choose the chairman of National Reconstruction Authority (NRA), an organization with mandate to oversee the overall post disaster reconstruction, led to further delay in carrying out reconstruction activities. This was mainly due to political tussle between major political parties on who would head the organization as it involved mobilizing large funds. Only in December 2015, NRA got established.

NRA then came up with a detailed recovery plan published in the Post Disaster Recovery Framework (PDRF) 2016-2020. The framework comes with strategic recovery objectives and describes in detail the policy decisions, financial managements, institutional arrangements and implementation and monitoring mechanisms to oversee the overall reconstruction and recovery process. PDRF was largely based on the Post Disaster Needs Assessment (PDNA) report prepared by the NPC within few months after the earthquake in 2015. This report not only documented the extent of damage received and accounted the financial needs for reconstruction. It also provided initial recovery strategies, which formed the basis for PDRF report. Both these documents were hugely influenced from the Sendai Framework for Disaster Risk Reduction (SFDRR) adopted in March 2015.

The Reconstruction and Rehabilitation Policy drafted in 2015 brings together all the actors including Government of Nepal, national and international NGOs, aid agencies, pri- vate sector, volunteers and communities to join hands and work for the recovery and reconstruction of earthquake affected Nepal. This policy identifies that the approach to housing reconstruction in Nepal will primarily be 'ownerdriven' meaning the government will provide technical and financial assistance but the main responsibility of reconstruction lied in the hands of home owners who must build their new homes complying to the National Building Code and house designs approved by the NRA. This approach of reconstruction being owner driven and with active engagement of the community, private sectors and volunteer was adopted in a hope to build ownership, increase participation and ensure social cohesion during the recovery process.

However, due to political instability, complex institutional arrangements and many other factors, recovery has been slow. People spent following years and some still continue to live in those temporary shelters and reconstruction of houses has happened in a less than satisfactory pace in most places. Despite the sluggish pace, some areas have used this disaster experience as an opportunity to build back better. While many places are characterized by difficulty in reconstruction due to poverty, lack of manpower and scattered settlements, some have overcome these challenges through community action and opted to build integrated settlements.

This paper brings lessons from the case study of Giranchaur village from Melamchi municipality in Sindhupalchowk district where active community engagement and utilization of social capital and networks have resulted in reconstruction of houses into integrated settlements that have attracted interest nationally and internationally. The reconstruction process is assessed with reference to available literature on community engagement and role of social capital and networks in post disaster recovery and practical lessons from international disaster experiences. 


\section{LITERATURE REVIEW}

Traditional literature on disaster recovery has mainly looked at the role of states and governments and their capacities to recover from disasters. Aldrich (2012) briefly summarizes the major factors discussed in traditional literature that affected faster recovery. He finds major scholarly discussion mainly focusing towards quality of governance, socio-economic status of victims and amount of international aid provided by outside institutions.

While there is little debate on the importance of these factors, increasing interest can be seen towards newer approaches to disaster recovery such as social capital approach that promotes community engagement through utilization of existing networks (formal and informal) of trust and reciprocity. Researches highlighting the importance of newer approaches put forward the argument that giving attention to these factors during post disaster situations lead to more effective and efficient collective responses and more sustainable outcomes. They also warn that failure to address the existing social context in disaster hit communities may lead to inefficient use of valuable resources and result to undesired outcomes (Mulligan, Ahmed, Shaw, Mercer, \& Nadarajah, 2012; Skoric \& Kupresanin, 2018).

Communities are the first responders to disasters. The 1995 Kobe earthquake took lives of 6437, injured 43,792 people and damaged more than 140,000 houses (Kako \& Ikeda, 2009). This disaster is said to have typically marked the beginning of realization on importance of communities in dealing with disasters in Japan as remarkably "over 80 percent of victims buried under collapsed building were rescued by neighbors" (Ishiwatari, 2012). With this realization Japanese government promoted the activity of existing community based organizations and the establishment of Non-profit Organizations (NPOs) and Non-governmental Organizations (NGOs) in assisting the communities to be resilient to disasters. Norris, Stevens, Pfefferbaum, Wyche, and Pfefferbaum (2008) also found that social capital; community resources, community bonds, roots and commitments positively contribute towards building adaptive capacities and resilience of communities to disasters.

Aldrich (2012) researched on the role of social capital and networks in disaster recovery. His research on the 2011 Tohoku Earthquake in Japan followed by a tsunami further supports the aforementioned argument. His research found many people surviving the disaster because of the "actions of others". People were mainly rescued by other people who were familiar and within their existing networks. The role of community however, is not just crucial in immediate rescue and relief stage but also in long-term recovery. A com- parative study of Nakagawa and Shaw (2004) on the Gujarat earthquake of 2001 and 1995 Kobe earthquake showed that the role of communities was in fact "the most important roles among concerned stakeholders" at every stage of disaster rescue, relief and rehabilitation.

Community action or lack of it is found to considerably affect the recovery process. Gismondi (2012), investigated community behavior after 2004 Chuetsu earthquake in Kawaguchi, Japan and found out that everyday social relationships, social interactions and organizations were among the main causes of difference in community organization during recovery process. Place with strong social relations and well-defined structure of the local society performed better in rehabilitation process. Aldrich and Meyer (2015), too argue that existing social ties, which include networks of both formal and informal groups in the community, are of relevance to build capacity of communities to influence policy makers and access vital economic and informational resources for post disaster recovery.

Minamoto (2010) studied the relationship between livelihood recovery and social capital in post-tsunami Srilanka, which was triggered by an earthquake in 2004. Her survey findings state that formal network in the community, leadership, and trust of community-based organizations has positive linkages to disaster recovery. Her study findings particularly highlight the role of able leadership as significant to provide smooth services in post disaster situation to overcome risks of elite capture and negative effects of bonding social capital (emotional ties with family and friends). Hence, the role of bridging social capital (network among different social groups and organizational ties) and linking social capital (connection between citizen and those in power) is vital in this scenario to organize heterogeneous communities and attract external support from government or non-governmental institutions and make coordinated contextual interventions to disaster recovery (Aldrich \& Meyer, 2015; Aram \& Alibaba, 2018; Gil-Rivas \& Kilmer, 2016).

The role of existing social networks and importance of collective action in post disaster situations is hence vital to effective recovery. Norris et al. (2008) suggest that, "preexisting organizational networks and relationships are the key" to work together in post disaster recovery as they help to minimize challenges that may arise due to lack of trust with unfamiliar external organizations. In Nepal, the PDNA and PDRF reports' from the National Planning Commission (NPC) (2015) and National Reconstruction Authority (NRA) (2016) respectively can be seen to have kept the aforementioned factors in strong consideration to achieve its recon- 
struction objectives. PDNA report gave utmost priority to community participation by putting it as the first guiding principle to planning the post disaster recovery. With heavy influence from SFDRR, it gives special attention to concepts of 'building back better,' 'integrated model of recovery' and 'emphasis on communities' (Lam \& Kuipers, 2019; National Planning Commission (NPC), 2015). It states, "encourage the participation of communities by empowering them to take control of reconstruction of their houses and ensuring facilitation of ODR" (National Planning Commission (NPC), 2015). Hereby stating that Nepal government would facilitate the owner-driven reconstruction approach to encourage communities to take charge of their own recovery.

PDRF report further states the recovery vision to be "wellplanned, resilient settlements and a prosperous society". Strategic objectives to achieve the vision include "Restore and improve disaster resilient housing", "Strengthen the capacity of people and communities to reduce their risk and vulnerability and to enhance social cohesion", "develop and restore economic opportunities and livelihood" among others (National Reconstruction Authority (NRA), 2016). The main focus area of government action in the recovery process is largely on building safe structures, ensuring social cohesion, capacity building and providing livelihood support. It further states that an "approach to Community Based Organizations (CBOs) will be made in every settlement, to ensure community participation and ownership of reconstruction and recovery and at the same time enhance social cohesion to build resilient communities" (National Reconstruction Authority (NRA), 2016).

Hence, from the analysis of available scholarly literature and through study of policy documents of Nepal it can be seen that the role of communities and social networks in post disaster recovery and reconstruction is taking prominence in the policy making level. The paper looks to examine whether it is in operation on the field or not in the subsequent sections.

\section{METHODOLOGY}

This paper studies the two major sources of information on Nepal's post disaster recovery and reconstruction process, the PDNA, 2015 and PDRF 2016 reports to develop an understanding on the focus of Nepal's reconstruction policy and observes its implementation at the community level through data and information gathered from field visits. Utilizing scholarly sources of literature on disaster recovery, community engagement and social capital, the data and information gathered from field visits is analyzed to describe the nature of Nepal's reconstruction process and what key lessons can be learned on the role of community and networks in disaster recovery.

During field visits, direct observation and in-depth, semistructured interviews were carried out as instruments for primary data collection together with review of documents such as annual reports, project proposals, meeting minutes among others. A small sample of well informed key informants was preferred to suit this case study which involves rich description of case and is of exploratory nature. As stated by Streubert and Carpenter (1999), purposive or judgmental sampling can be adopted to carefully select the sample, which can provide best knowledge or firsthand experience on the subject of study in a qualitative research. Hence, 7 key informants and 28 villagers were interviewed, who were leading or directly involved in the reconstruction process.

Data was collected from two field visits; first in October 2017 and second in August 2018. The study area was identified in consultation with reconstruction stakeholders using the stakeholder map. After that, a well-informed sample was derived that included people such as government officers, NRA officials, leaders from CBOs, engineers, elected representatives and local village residents. The semi-structured interviews were open ended to allow freedom while answering but adequate measures were taken to prevent deviation from the main focus of study. During field visits, observation was done of the reconstruction sites and work in progress. Pictures of these activities were taken with consent and consent was also acquired to disclose the original identity of participants in this study.

Collected data was then organized into common concepts and divided into categories. Data was then reduced for conclusion drawing and presented in line with the literature reviewed. Data triangulation was adopted to develop understanding from multiple perspectives and avoid deviation from the main focus of study during data analysis. This formed the basis for how results are presented and described in the following section.

\section{RESULTS}

\section{Study Area}

Melamchi Municipality is located in southwest region of Sindhupalchowk district and is one of two municipalities in the district. This place was also very badly affected by the earthquake with official reports from the municipality citing death of 523 people and 12564 houses damaged, which also amounts to about $95 \%$ of the total houses in the municipality (Global Green Growth Institute, 2018). It has 13 wards as shown in Figure 2 the following page and Giran- 
chaur is a village in ward number 12 of this municipality. The total area of this municipality is 161.2 square kilome- ters in which ward no. 12 covers area of 14.87 square kilometers within this boundary.

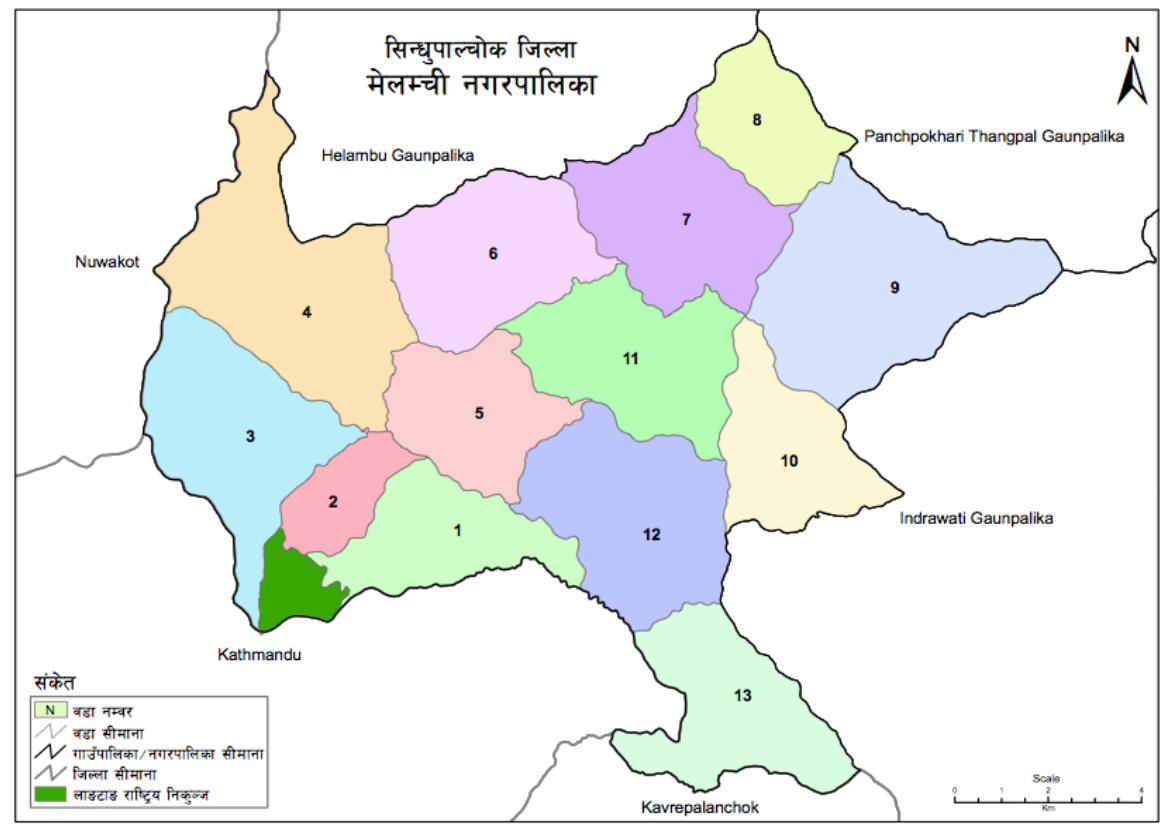

FIGURE 2. Map of Melamchi municipality with ward numbers and boundaries. (Source: Nepal in Data (2018))

Despite only being about $60 \mathrm{~km}$ away from the capital city Kathmandu, the area is rural and marked by poverty. 350 households live in this area where access to this village is a steep muddy and bumpy road, which is about $6 \mathrm{~km}$ from the Helambu highway.

In terms of caste and ethnicity Hill Brahmin, Tamang and Chhetri make the majority of population. More than 70 percent of the population is engaged in agriculture for their living but due to scattered landholdings and dependency on rain as a result of lack of irrigation facilities in hilly slopes, it is mainly subsistence farming with very little income generated. The main crops grown are rice in irrigable plain land, and maize and millet in hills. According to Central Bureau of Statistics (CBS), national census of 2011 showed that around 95\% people lived in their own houses but the houses mainly had foundations of mud-bonded bricks or stones (Central Bureau of Statistics (CBS), 2011). This was among the major reasons why almost all the houses were completely damaged by the earthquake, as the foundations were not earthquake resistant.

\section{Survivor's Account}

On Saturday, April 25, 2015, around 11:56 am, 7.8-magnitude earthquake hit the area. Janardan Tiwari, a permanent resident of Giranchaur recalls the day as a 'black day'. He says, "it was a complete chaos, the ground started shaking and houses started to crack. Dust blown from fallen houses engulfed the sky and we thought it was our end but luckily it was during the day and most of us were working outside our homes. Schools were closed as it was a holiday, otherwise, casualties would have multiplied and schools would have turned into mass graves". From his account the horrific experience people went through can easily be understood. However, their troubles didn't end with that major shake as hundreds of aftershocks followed. Despite that, people started to search for their loved ones and neighbors and began rescue of trapped and injured people.

Bidur Bhattarai, another resident recalls the initial days and nights they spent outside. He says, "We stayed by forming groups of neighbors and relatives and spent the initial days and nights eating and sleeping together in groups. Some set up tents from materials available, while others lived under the open skies". Nepal last had a major earthquake in 1988 when a 6.9 magnitude earthquake hit near the Nepal-India borders. Despite being in an earthquake prone zone, disaster preparedness was very poor in Nepal. Rural houses are mostly built under local knowledge by unskilled masons without supervision from engineers. Evacuation centers are almost non-existent and for people like Bidur, who haven't had any previous disaster experience, they did not know the correct course of action. All he knew was to be united with the people in the neighborhood and help each other in such time of need. 
The few whose houses had cracks but were contemplating to renovate and live in the same house got another setback as the aftershock of magnitude 7.3 hit on May 12, 2015. After 17 days of the main quake and this time the epicenter was Sindhupalchowk itself. This led to further damage and almost all the houses became unlivable leaving people homeless and forcing to live under makeshift temporary shelters. Sabin Tiwari recalls, "It was the second major quake that did even more damage as epicenter was here and it further damaged the already weak structures leaving our hopes of getting back to our homes in tatters".

\section{Relief and Immediate Recovery Efforts}

The earthquake victims set up temporary shelters, mostly made from collecting the materials that could be reused from their damaged houses or materials that were locally available such as mud, bricks, wood etc. Government declared to provide Nepalese Rupees (Rs) 15000 (approximately USD 150) to buy Corrugated Galvanized Iron (CGI) sheets, which is typically used for roofing in Nepal, in order to construct temporary shelters for those without homes. The makeshift shelters were small and often congested. People lived a very uncomfortable life in these shelters. During monsoon, when it rained, the iron sheets would make heavy noises and during summer the heat became unbearable. The situation however got even worse during winter as several deaths in temporary shelters were reported in Sindhupalchowk due to cold.

Due to these deaths, government declared to provide additional Rs.10000 to the victims to buy warm clothes for winter. After the establishment of NRA, government then declared to provide Rs 200,000 as cash assistance for reconstructing houses. This was later increased to total of Rs 300,000 to be provided in installments following inspection from NRA officials and engineer. Rajesh Sharma, municipal engineer of Melamchi municipality mentions, "the first tranche of Rs 50000 is provided to construct foundations. After inspection, if the house conforms to NRA approved model-housing designs and building code, second tranche of Rs 150000 would be approved. It would then be followed by another inspection before approving third and final tranche of Rs 100000".

\section{Community Engagement and Road to Long-term Recov- ery}

On June 9, 2015, about one and a half month after the first earthquake and about one month after the major aftershock of May 12, around 150 community members gathered for a meeting to discuss about future course of action in re- constructing the damaged village. Ram Bahadur Tamang, a community leader who is currently the ward chairman of ward number 12, elected in the local election of 2017, fondly remembers that meeting. He says, "that meeting conceived the idea of re-building this village. Not just rebuilding to previous condition but building it better than before". The idea was to rebuild in such a way that the problem of scattered settlement in Giranchaur, which had made access to services and infrastructures difficult to reach everyone would be solved. They agreed upon building integrated settlements in blocks by pulling in people living in a scattered manner. They agreed to prepare proposals and start campaigning to gain external support. Radio Melamchi, a local FM radio station played a crucial role in creating awareness and disseminating the information to wider public.

The local people identified plot of land nearby which were relatively plain and suitable for housing to each neighborhood for reconstructing the houses. Giranchaur has people coming from different castes and ethnicities. Their cultures and traditions, lifestyle varies considerably. Furthermore, people had their farmlands close to their previous homes and did not want to leave their place of origin. Hence, to respect all this, they decided to divide settlements into blocks where people from separate neighborhoods could live near to their current place, and live together with their neighbors and relatives. However, to reach to this conclusion, it took a little time to convince everyone initially but ultimately everyone agreed upon recognition of benefits of living in an integrated housing. They agreed that doing this would ensure no threat to the existing balance and harmony in the community.

\section{Philanthropy and community engagement}

Sitaram Kattel and Kunjana Ghimire, famous television personalities who are a real life couple and are commonly known by their character names 'Dhurmus' and 'Suntali' accordingly are a household name in Nepal. They rose to fame doing comedy serials and after the earthquake they decided to utilize that fame to support victims of the earthquake. Their foundation 'Dhurmus Suntali Foundation' was established and they conducted various relief works and charity events by calling on the Nepali Diaspora living and working abroad to support for the cause through donations. They contacted the NRA, Melamchi Municipality and other related stakeholders and went searching for an appropriate place where they could support long-term recovery through reconstruction of houses. Since Sindhupalchowk was the worst hit district they wanted to support a needy 
community there. NRA officials were already aware of the plans and activities of community of Giranchaur. The indigenous Tamang community was relatively backward in socio-economic conditions and most people were living under poverty. Therefore NRA introduced the community proposal and the community leader Ram Bahadur Tamang to the foundation. Following that a model reconstruction work with large-scale attention started which turned into an example for others to follow. This reconstruction project was named 'Unified Giranchaur Model Village'.

This reconstruction project built 65 earthquake resistant houses including a community hall for 384 people in seven months. This was remarkable given the sluggish pace of reconstruction elsewhere. The project started on April 24, 2016 and on October 28, 2016 the President of Nepal handed over the houses to residents in a function with presence of the celebrity duo. The two-storied houses cover 1056 square feet of area. It has 5 rooms and a toilet. Each house has a solar panel, a tap for running water, small garden in front of the house and is connected by road. They have 3 parks, 4 public toilets, 3 parking areas and a view tower in the village. Investment per household for the project was Rs 778100, which was approximately 7500 US dollars (Dhurmuss Suntali Foundation, 2019). The village is divided into three blocks, Namely A, B and C. Block A has 23 houses, $B$ has 27 houses and $C$ has 14 houses.

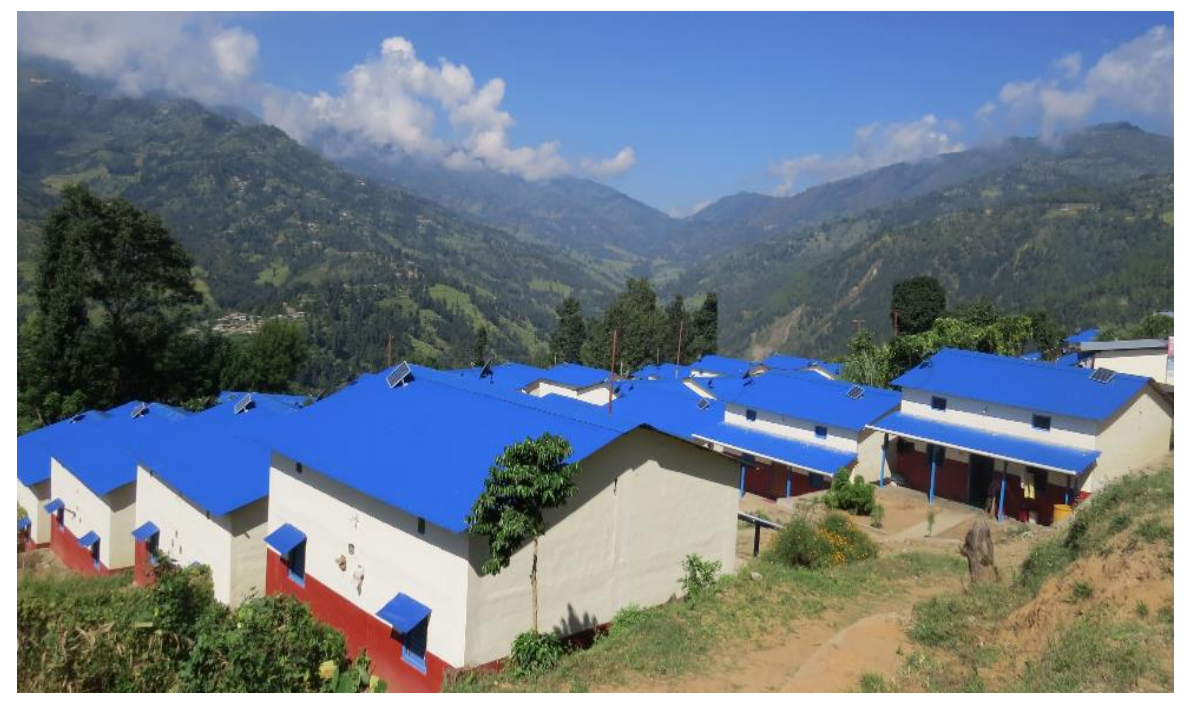

FIGURE 3. Completed houses of unified Giranchaur model village1

Jeet Bahadur Tamang, who lives in this model village, expresses his joy by saying, "I am very happy to have a home to live now as I wouldn't be able to build one like this by myself. I am even happier as all the community members got one house for themselves and I get to live together with them. This model village shows that if people get united and work for each other, miracles are possible in real life". In fact his words are true because the houses weren't just made by money collected from Nepalese in and outside the country through the foundation but through mass mobilization of community members and government institutions.

The community formed a management committee to oversee the reconstruction and later the maintenance of the village after completion. Ram Bahadur, was chosen the chairman of the committee. Lal Bahadur Tamang was chosen the secretary in that committee. He recalls telling the community members, "the community needs to take ownership of the project and actively participate in the reconstruction process. We cannot just act victim and receive the sup- port without contributing anything. If others are ready to contribute their hard earned money to build us houses, we have to show that we deserve that by working tirelessly and make this project a success". In fact people did work hard as they decided to do voluntary works. One person from each household worked around twelve hours a day voluntarily until the completion of the project. The celebrity duo as well sat in the community and worked at the sites, which encouraged others to volunteer as well. Nepal Army, Armed Police Force, Nepal Police and other organizations offered to work as volunteers in various times which led to successful completion of reconstructing the model village.

After its completion, the village has attracted several tourists and guests who come to visit the village. Residents have organized home stay programs and that has also contributed to generating income. Film and music video shooting crews too come to the village and all this has contributed to the livelihood recovery of the local people. 


\section{Integrated settlements}

Seeing the community's idea of building integrated settlements bearing fruits due to active community engagement and external support in Unified Giranchaur Model Village, other neighborhoods of Giranchaur too started to actively work for their own reconstruction efforts. On February 2017, after numerous consultation and administrative delays 'Community Reconstruction Tourism Promotion Project' was established to reconstruct another integrated settlement for 135 households in Giranchaur. Raj Kumar Bhattarai led this reconstruction committee as a chairman that has four other sub-committees to oversee as many blocks in this settlement.

Like the Model Village, this project too adopted similar approach to creating blocks for each neighborhood with people choosing to live in the block that is most convenient and comfortable to them. However, significant differences to the Model Village were on the type of houses, financial man- agement and other procedural differences. This wasn't going to be built under immense media coverage or through public donations alone. It wouldn't attract the level of volunteers the other project did and also any leverage that a celebrity led project would get. Furthermore, RCC model houses were going to be built which required more costs. Official approval was also required from the municipality to pass the designs and for that royalty must be paid.

However, there were many similarities to the other project. Most important one was the determination and active engagement of the people. The residents were ready to offer voluntary services on works that did not require professional experience on housing construction. One household one-worker approach was practiced with each household promising 250 persons work. One person of work was equivalent to 9 hours of work. This meant money spent on hiring labor was considerably reduced.
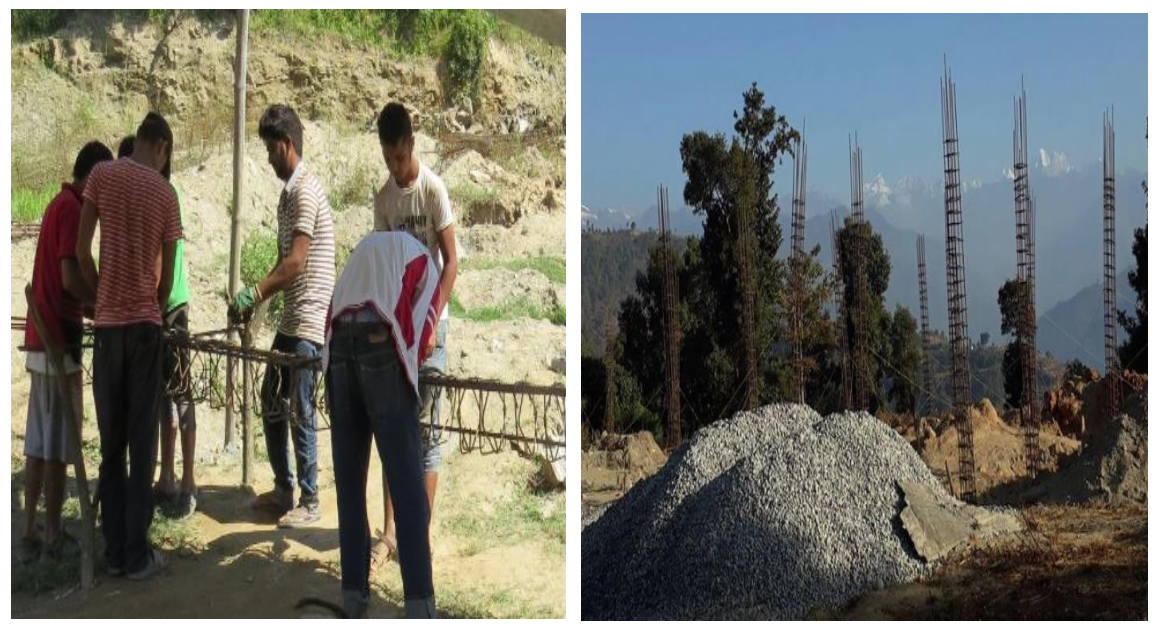

FIGURE 4. Youths engaged in work to prepare iron pillars (left) and pillars ready for concrete (right)

NRA approved their proposal with detailed financial plan, physical infrastructural plan and managerial plan for integrated settlement, in accordance with 'Integrated Settlement Development Procedure' framework that was formulated to encourage integrated settlement if government criteria were met. If ten or more families proposed to build an integrated settlement and fulfilled the government criteria's, NRA would approve and support such proposals. According to Dangal (2019), Such projects would receive cash assistance from NRA of Rs 500,000, Rs 400,000 and Rs 350,000 depending on whether the proposals were made from Mountainous, Hilly or Terai regions respectively.

Owing to their united effort, determination and constant pursue of searching for external help, several national and international organizations sought to help them financially and in kind to reconstruct the houses. A Thai organization provided them 48 water tanks and rubber pipes. Another organization named Global Friends of Tilganga pledged to provide total of Rs 30 million (approx USD 3million) for the project.

Dr. Govinda Pokharel, former CEO of NRA and former chief of National Planning Commission, who is an advocate of integrated settlement in Nepal after the earthquake, stated, "integrated settlements developed by the government has every chance of turning unsuccessful" citing examples of settlements constructed after earthquakes in India and Pakistan. However he remarked, "that the Giranchaur locals have themselves envisioned and led this project will ensure its success and sustainability" (Setopati, 2019). NRA engineers who regularly come to monitor the construction 
progress agree with this statement as they have seen firsthand the dedication from the locals.

As of October 2019, people have started moving in to houses that are completed while others are nearing completion in this project. Photo 3 below shows houses nearing completion as of May 2019. The community has a long-term vi- sion for this settlement and will work for livelihood recovery through income generation activities. Home stay programs and tourism promotion are identified as potential areas together with vegetable farming, poultry and animal husbandry for entrepreneurship development.

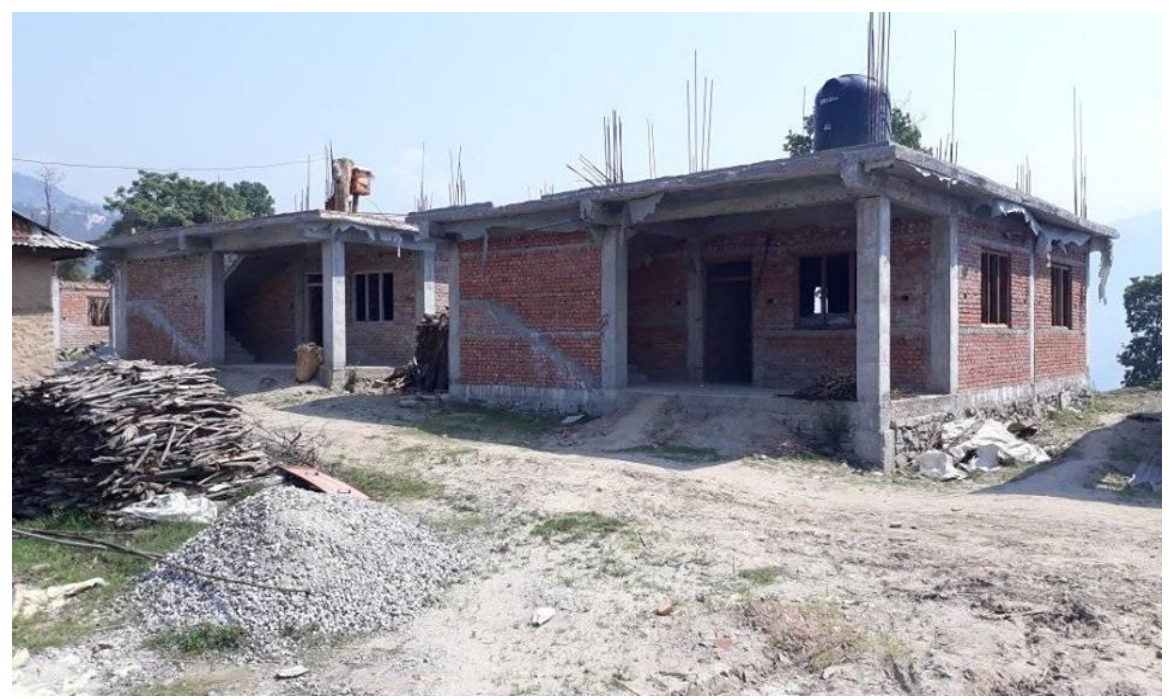

FIGURE 5. Houses nearing completion as of May 2019. (Source: Bidur Bhattarai, May 2019)

Furthermore, a community library and resource center building is near completion. This will particularly help to nurture knowledge and develop skills of the youth in the community. Sudarshan Tiwari another resident of this settlement says, "At present, 30 young students are learning basic computer skills. After the building is fully completed, we will have thousands of books in the library from which, our youths can gather knowledge and information on various fields. Human resource development is key to growth of any community and we are sure this is going to contribute heavily to that".

Besides these two settlements, there is another integrated settlement under construction for 70 households with active involvement of locals in Giranchaur. Ward Chairman Ram Bahadur Tamang is proud to be the leader of a ward that has been an example for other areas in post disaster reconstruction. He says, "out of 350 households, 270 households have already adopted integrated settlements. I aim to provide necessary support in building infrastructures for development of this area so that livelihood of locals improves and the settlements becomes sustainable".

\section{DISCUSSION}

The findings from this study highlighted the growing importance of community engagement in post disaster reconstruction and recovery through existing social capital and networks present in the communities. While there is not much debate that the most important determining factors for carrying out the post disaster recovery in an effective way is the ability of government, the role of communities is vital to ensure effective and sustainable recovery. Understanding the local context and engaging the community in their own relief and recovery activities motivates them, contributes to build a sense of ownership and help them overcome the trauma from earthquake (Yeoh, 2012). It also further contributes to empower earthquake victims from passive recipients of aid to active agents of change (Aldrich, 2012). This proved true from the experience of earthquake victims of Giranchaur who initiated their own recovery efforts and engaged actively to build integrated settlements. Role of local leadership was an important factor determining the pace of reconstruction and ability to garner external support. Able leadership provided by Ram Bahadur Tamang was vital to organize and mobilize the community. His efforts to reach out to government institutions and other organizations to support their recovery initiatives was noticed and that led to Dhurmus Suntali Foundation choosing to build the model village in Giranchaur. Therefore, the static social capital present in the community was transformed into active social capital through the "mediating agency" of local leadership (Krishna, 2002). This later snowballed to attract many volunteers and donors to 
support community initiatives in other neighborhoods of Giranchaur. Thus, fruits of linking social capital can be seen in Giranchaur. Raj Kumar Bhattarai too provided able leadership and accessed resources outside of the community. Not just formal leadership, but various other informal leaders contributed actively to organize and engage community members and kept their motivation high to overcome various challenges. Bridging social capital was active to connect and unite people from various caste, religion and ethnicity in the recovery efforts of the community.

Role played by celebrities Dhurmus and Suntali led to a wave of philanthropy and volunteerism in the country. Social unity and sense of community got strong in difficult times. People unaffected from earthquake showed compassion and volunteered through physical labor in re-building the houses. Others donated their hard earned money for the relief and recovery activities. Neighbors came together to overcome the trauma by staying together in initial days after earthquake. Later helped make each other's temporary shelters and continued their engagement to making integrated settlements. This brought awareness among people that reconstruction and recovery is not a government led project but much more than that. It is a combined national effort with communities at the heart of it.

Without understanding the local context, existing social networks and without active consultation and engagement of communities, recovery efforts in various parts of the world have significantly failed in achieving their objectives with some proving counterproductive. Despite having valuable resources, it could be directed to damaging projects that do not yield desired outcomes. Long-term housing meant for elderly survivors of Kobe earthquake in 1995 had such an experience. 240 survivors who were relocated to this housing died lonely deaths (Aldrich, 2011). Postdisaster housing reconstruction after 2004 Indian Ocean earthquake and Post disaster housing reconstruction in Haiti after 2010 earthquake are some recent examples that showed similar challenges. Key learning lessons from them involved decision-making and social planning procedures needing to engage communities and consider their local needs, socio-economic and cultural factors (Mulligan et al., 2012). Nepal's current overall performance too hasn't been encouraging and therefore, the example of Giranchaur has huge significance.

\section{CONCLUSION}

The fact that integrated settlement was an idea initiated by the communities of Giranchaur village, they have immense pride and ownership over their reconstruction project. This has positive impacts on long-term sustainability. They have planned the settlement as per their local need and respecting the communal harmony and balance. They have longterm vision for economic recovery, environmental consideration and social cohesion. Therefore, the role of government and other institutions was of facilitation. This case shows that bottom-up community initiatives with support from outside show significantly more positive outcomes. Aldrich (2012) argues in similar light that rather than just focusing on physical infrastructure, if government interventions are more social capital focused it may be more cheaper yet yielding longer term impacts. Gismondi (2012) further believes that community-driven plans supported by local governments are key to raising public awareness. This yields more participation and response from the public, which helps them better prepare for disasters and recover quickly when it occurs.

\section{LIMITATIONS AND RECOMMENDATIONS}

The long-term recovery and reconstruction of communities should be carried out in a careful manner to ensure active engagement, fairness and equity. Failing to do so can result to damage in existing social structures. Apart from the efforts to constructing disaster resistant houses, schools, hospitals and other physical infrastructures, special attention must be given to aspects of social justice. To ensure sustainability, raising awareness about future vulnerabilities and building community resilience is also vital. However, effective recovery with active community engagement shouldn't just be a conceptual rhetoric but an operational idea with clear implementation process that yields positive outcomes long into the future. Therefore, this study recommends further research in finding practical implications of social capital and importance of community engagement in disaster recovery through study of post-disaster recovery experiences of communities in different settings.

\section{REFERENCES}

Aldrich, D. P. (2011). The power of people: Social capital's role in recovery from the 1995 Kobe earthquake. Natural Hazards, 56(3), 595-611. doi:https://doi.org/10.1007/s11069-010-9577-7

Aldrich, D. P. (2012). Social capital in post disaster recovery: Towards a resilient and compassionate east asian community. In Y. Sawada \& S. Oum (Eds.), Economic and welfare impacts of disasters in east asia and policy responses (p. 157-178). Jakarta, Indonesia: ERIA. 
Aldrich, D. P., \& Meyer, M. A. (2015). Social capital and community resilience. American Behavioral Scientist, 59(2), 254-269. doi:https://doi.org/10.1177/0002764214550299

Aram, R., \& Alibaba, H. Z. (2018). Investigating sustainability of the traditional buildings in Kermanshah, Iran. International Journal of Humanities, Arts and Social Sciences, 4(6), 235-244. doi:https://dx.doi.org/10.20469/ijhss.4.10002-6

Central Bureau of Statistics (CBS). (2011). National population and housing census 2011. Kathmandu, Nepal: National Planning Commission.

Dangal, D. (2019). Quake victims pressing for building integrated settlement. Retrieved from https://bit.1y/2ZQS6NO

Dhurmuss Suntali Foundation. (2019). Unified giranchaur model village. Retrieved from https://bit. Iy/2QnAaaQ

Gil-Rivas, V., \& Kilmer, R. P. (2016). Building community capacity and fostering disaster resilience. Journal of Clinical Psychology, 72(12), 1318-1332. doi:https://doi.org/10.1002/jclp.22281

Gismondi, M. (2012). Investigating rural community behaviour after the 2004 Chuetsu earthquake: A case study of Kawaguchi town, Japan. Social Geography Discussions, 7(1), 39-68. doi:https://doi.org/10.5194/sg-7-1-2012

Global Green Growth Institute. (2018). Melamchi municipality, Nepal: Situation analysis for green municipal development. Seoul, South Korea: Global Green Growth Institute.

Ishiwatari, M. (2012). Government roles in community-based disaster risk reduction. In R. Shaw (Ed.), Community-based disaster risk reduction (p. 19-33). Bingley, UK: Emerald Group Publishing Limited.

Kako, M., \& Ikeda, S. (2009). Volunteer experiences in community housing during the Great Hanshin-Awaji Earthquake, Japan. Nursing \& Health Sciences, 11(4), 357-359. doi:https://doi.org/10.1111/j.1442-2018.2009.00484.x

Krishna, A. (2002). Active social capital: Tracing the roots of democracy and development. New York, NY: Columbia University Press.

Lam, L. M., \& Kuipers, R. (2019). Resilience and disaster governance: Some insights from the 2015 Nepal earthquake. International Journal of Disaster Risk Reduction, 33, 321-331. doi:https://doi.org/10.1016/j.ijdrr.2018.10.017

Minamoto, Y. (2010). Social capital and livelihood recovery: Post-tsunami Sri Lanka as a case. Disaster Prevention and Management: An International Journal, 19(5), 548-564. doi:https://doi.org/10.1108/09653561011091887

Mulligan, M., Ahmed, I., Shaw, J., Mercer, D., \& Nadarajah, Y. (2012). Lessons for long-term social recovery following the 2004 tsunami: Community, livelihoods, tourism and housing. Environmental Hazards, 11(1), 38-51. doi:https://doi.org/ 10.1080/17477891.2011.635186

Nakagawa, Y., \& Shaw, R. (2004). Social capital: A missing link to disaster recovery. International Journal of Mass Emergencies and Disasters, 22(1), 5-34.

National Planning Commission (NPC). (2015). Post disaster needs assessment. Kathmandu, Nepal: National Planning Commission.

National Reconstruction Authority (NRA). (2016). Post disaster recovery framework 2016-2020. Kathmandu, Nepal: National Reconstruction Authority.

Nepal in Data . (2018). Administrative map-Melamchi Sindhupalchok, Province 3. Retrieved from https ://bit. ly/39GljQ7

Norris, F. H., Stevens, S. P., Pfefferbaum, B., Wyche, K. F., \& Pfefferbaum, R. L. (2008). Community resilience as a metaphor, theory, set of capacities, and strategy for disaster readiness. American Journal of Community Psychology, 41(1-2), 127-150. doi:https://doi.org/10.1007/s10464-007-9156-6

Setopati. (2019). Tilganga hands over Rs one crore for reconstruction of Giranchaur. Retrieved from https://bit.1y/ 2 tsy7sz

Skoric, J., \& Kupresanin, J. (2018). Social work in educational system of the Balkans - Is social worker needeed in schools? International Journal of Humanities, Arts and Social Sciences, 4(6), 245-252. doi:https://dx.doi.org/10.20469/ijhss.4 .10003-6

Streubert, H. J., \& Carpenter, D. R. (1999). Qualitative research in nursing: Advancing the humanistic imperative. Philadelphia, PA: Lippincott.

Yeoh, G. (2012). Lessons learned: The 2011 disasters in Tohoku, Japan. Retrieved from https://bit. ly/2SOwe6 